Craig L. Irish MD FRCPC, John M. Murkin MD FRCPC, Gerard M. Gujraudon MD FRCSC

\title{
Anaesthetic management for surgical cryoablation of accessory conducting pathways: a review and report of 181 cases
}

Pre-excitation disorders have an estimated prevalence of 0.15 per cent. Advances in electrophysiological mapping and the increasing sophistication of surgical techniques have resulted in an increasing role for definitive surgical treatment. A retrospec. tive chart review of 181 patients undergoing 197 procedures for surgical ablation of accessory atrioventricular pathways between June 1981 to June 1986 was performed. Mean age of the patients was 30 years (range 6-66) with a preponderance of males ( 59 per cent). Associated cardiac disease was found in 18 (9.9 percent) patients. Induction of anaesthesia employed either a barbiturate-relaxam ( 83 per cent) or a narcotic-benzodiazepinerelaxint (17 per cent) and was uneventful in all cases. In 14 per cent of cases a pure narcotic relaxant technique was employed for maintenance of anaesthesia. whereas a balanced technique with isoflurane (29 per cent), enflurane (34 per cent), or halothane (22 per cent) was utilized for the remainder. Muscle relaxation was provided by d-rubocurarine in 35 (18 per cent) procedures and pancuronium in the remaining 162 ( 82 per cent) procedures. There was no significant correlation between intraoperative arrhythmias and type of ancesthetic used. Although recognizing the potential for malignant arr hythmias, our experience (within the confines of a retrospective analysis) suggests that the majority of these patients can be managed successfilly using standard anaesthetic techniques.

\section{Key words}

SURGERY: cardiac; HEART: arrhythmia, treatment; ANAESTHESLA: cardiac.

From the Departments of Anaesthesia and Cardiothoracic Surgery, University Hospital, University of Westen Ontario, London, Ontario.

Address correspondence to: Dr. John M. Murkin, Department of Anaesthesia, Unjversity Hospital, P.O. Box 5339, Station "A", London, Ontario N6A 5A5.

Presented in part at the 1987 Annual Meeting of the Canadjan Anaesthetists' Society in Calgary. Alberta.
Since the original description in 1930 of the WolffParkinson-White (WPW) syndrome' and its variants (collectively entitled the pre-excitation syndromes PES), a more complete understanding of the electrophysiclogical basis behind these disorders, as well as their clinical implications, has been achieved. While it is generally considered that most patients follow a benign course, 40-80 per cent can have frequent and disabling supraventricular tachycardia. ${ }^{2}$ Furthermore, reports of syncope and ventricular fibrillation with sudden death attributable to the PES are now well documented. ${ }^{3,4}$ Advancements in electrophysiology (EP) have allowed identification of the subset of WPW patients with such a malignant potential. As such, an increasing number of patients are presenting for surgical ablation of accessory pathways under general anaesthesia. In addition, with a general incidence of 0.15 per cent (variously reported as $0.01-0.31$ per cent $)^{5-9}$ the community anaesthetist may be faced with a patient with WPW syndrome for noncardiac surgery.

\section{Methods}

After consideration by the University Health Sciences Standing Committee on Human Research, our experiences with 181 patients with documented WPW syndrome undergoing 197 procedures for surgical ablation of accessory atrioventricular pathways (AAP) over the five-year period from June 1, 1981 to June 1, 1986 were reviewed by a retrospective chart search in which the anaesthetic record, ICU record and admitting history were examined. Chi-square contingency tables were constructed to assess the association of anaesthetic agents or surgical technique with the occurrence of arrhythmias. Our early experience with 40 procedures for which the open heart technique was used was compared with 157 procedures in which the more recent closed heart (epicardial) technique was used. The epicardial approach obviates the need for aortic cross-clamping and cardioplegia, thus minimizing the risk of inadvertent heart block by allowing continuous monitoring of the electrocardio- 
gram. Surgery can be performed with normothermic cardiopulmonary bypass (CPB) or no CPB in selected cases, thus avoiding hypothermic $\mathrm{CPB}$, the use of cardjoplegia, and aortic cross-clamping. Mone complete discussions of the surgical technique have recently been published. ${ }^{6.7}$

\section{Results}

The 181 patients ranged from 6 years to 66 years of age with a mean age of $30 \pm 12$ (SD) years. There were 107 males ( 59 per cent) and 74 females ( 41 per cent). Eighteen (9.9 per cent) patients had associated cardiac disease including: Ebstein's anomaly (three); atrial septal defect (ASD-ostium secundum) (one); aortic valvular stenosis? insufficiency (three); mitral valve prolapse (three); mitral valve stenosis (two); cardiomyopathy (two); coronary artery disease (three); and left ventricular aneurysm (one). Concomitant open heart surgical procedures, in addition to ablation of accessory pathways, included the correction of Ebstein's anomaly, closure of an ASD, aortic valve replacement, coronary artery surgery and a left ventricular aneurysmectomy. For the purposes of this review the seven patients who underwent concomitant open heart surgical procedures were excluded from further analysis. The associated cardiac disease in the remaining 11 patients was deemed not to warrant surgical intervention.

Symptomatology attributable to the pre-excitation syndromes was varied as can be seen in Table $I$ and had been present for a mean duration of $11 \pm 9$ years ( 2 weeks -46 years).

Medical management of these patients can be seen in Table II. There were 18 (ten per cent) reports of severe drug reactions or allergies referrable to the antiarrhythmics noted on the admission histories. To negate their interference with intraoperative EP mapping all antiarrhythmics were discontinued $48-72$ hours prior to surgery and in the case of amiodarone a drug-free period of 14 days was used.

Premedication in the immediate preoperative period varied considerably. Patients received no premedication prior to 34 ( 17 per cent) of the surgical procedures whereas in the remainder the following were administered alone or in combination: a benzodiazcpine 102 (52 per

TABLE I Symptomatology

\begin{tabular}{lrl}
\hline & $n$ & $\%$ \\
\hline Palpitations & 180 & 99 \\
Presyncope/syncope & 96 & 53 \\
Chest pain & 51 & 28 \\
Dyspnoea & 53 & 29 \\
Requiring cardioversion & 38 & 21 \\
Previous cardiac arrest & 7 & 3.9 \\
\hline
\end{tabular}

TABLE II Medical management

\begin{tabular}{lrl}
\hline & $n$ & $\%$ \\
\hline Beta adrenergic blockers & 103 & 57 \\
Veraparil & 64 & 35 \\
Digoxin & 50 & 28 \\
Disopyramide & 50 & 28 \\
Quinidine & 48 & 27 \\
Procainamide & 21 & 12 \\
Propaficnone & 6 & 3.3 \\
Encrinide & 2 & 1.1 \\
Amiodarane & 22 & 12 \\
None & 12 & 6.6 \\
\hline
\end{tabular}

cent); narcotic 109 (55 per cent); scopolamine 52 (26 per cent); droperidol 33 (17 per cent); and/or phenergan two (one per cent).

Intraoperalive monitoring in all cases included a 5-lead electrocardiogram, radial arterial line, urinary catheter, and a rectal $+i-$ oesophageal temperature probe. In 172 ( 87 per cent) cases a central venous pressure line was inserted via the internal or external jugular veins and in 25 (13 per cent) cases a thermodilution pulmonary artery catheter was utilized. A barbituate-relaxant (thiopentonesuccinylcholine) technique with low-dose supplemental narcotics was used for induction of anaesthesia in 163 (83 per cent) cases. A further 27 (14 per cent) were induced using a narcotic-benzodiazepine-relaxant (fentanyldiazepam-pancuronium) technique while the remaining seven (three per cent) were induced using inhalational isoflurane as part of an experimental protocol. There were two episodes of supraventricular tachycardia prior to induction, and single episodes of atrial fibrillation and supraventricular tachycardia (SVT) following induction of anaesthesia. The latter were felt to be due to mechanical stimulation of the heart during central line placement. No hypotensive problems were reported using any of the induction techniques.

Anaesthesia was maintained using a balanced technique with inhalation of a volatile agent and moderate dose narcotic supplementation in 169 (86 per cent) cases, whereas, in 28 (14 per cent) a pure narcotic-relaxant technique was used. The volatile halogenated anaesthetics used wcrc halothane 44 (22 per cent); enflurane 67 (34 per cent); and isoflurane 58 ( 29 per cent). Ventilation with air-oxygen mixture was used with the pure narcoticrelaxant, whereas a nitrous-oxide-oxygen mixture was used almost exclusively as the carrier gas with the inhalational technique. Muscle relaxation was provided by d-tubocurarine in 35 (18 per cent) procedures and pancuronium the remaining 162 ( 82 per cent) procedures.

Mean operative time was found to be $4.6 \pm 1.0$ hours using the closed-heart technique as compared to $5.2 \pm 1.3$ hours with the open-heart technique. Similarly, mean 
TABLE III Episodes of arrhythmia and conduction disorders

\begin{tabular}{llc}
\hline & Open $(n=40)$ & Closed $(n=157)$ \\
\hline SWT & 6 & 18 \\
Atrial fibrillation/flutter & 4 & 7 \\
Ventricular fibrillation & 1 & 4 \\
A-V block & & \\
- transien: & 2 & 2 \\
- permuntent & 2 & 0 \\
\hline
\end{tabular}

cardiopulmonary bypass times were $79 \pm 38$ minutes and $99 \pm 48$ minutes respectively. Furthermore, no cardiopulmonary bypass was required in 32 (20 per cent) procedures using the closed-heart technique.

Intrapperative anhythmias and conduction disturbances requiring pharmacological therapy or cardioversion were documented in the anaesthetic records of 46 ( 24 per cent) procedures as detailed in Table III. The incidence of 37 per cent seen with the open-heart procedures was significantly higher than the 20 per cent found with the closedheart approach $(\mathrm{p}<0.05)$. The anaesthetic employed when the disturbances were noted as a percentage of their total use were as follows: halothane 23 per cent (10); enflurane 19 per cent (13); isoflurane 24 per cent (14); and narcotic 36 per cent (10). Similarly arrhythmias were documented in 26 per cent (9) cases where d-tubocurarine was employed as the relaxant, and in 23 per cent (38) cases where pancuronium was used. There were no significant differences in the incidence of arhythmias between muscle relaxants and anaesthetic agents.

There were five episodes of ventricular fibrillation which required asynchronous cardioversion, and seven SVT associated with hyporension requiring synchronous cardioversion. Three permanent pacemakers were implanted, all in the open-heart group. Two were for complete A-V block while one was inserted as prophylaxis against brady-dysrhythmias. Two episodes of SVT necessitated remapping and further surgical cryoablation. Verapamil and propranolol were frequently used as an aid for electrophysiological mapping. SVT was treated with xylocaine twice. Hypotension immediately following dislocation of the heart while mapping prior to institution of cardiopulmonary bypass required phenylephrine or ephedrine in 16 per cent (39) of cases. Postoperatively all patients were admitted to the intensive care unit for overnight monitoring. Postoperative atrial arrhythmias occurred frequently, yet were transient in nature requiring no long-term therapy apart from two cases of atrial fibrillation necessitating ongoing digoxin therapy.

During normothermic cardiopulmonary bypass anticoagulation was assessed using activated clotting times (ACT). Average heparin dosage requirements to maintain an ACT $>400$ s was $367 \mathrm{IU} \cdot \mathrm{kg}^{-1} \cdot \mathrm{hr}^{-1}$. Average time to extubation was 9.0 hours. Nevertheless, 21 ( 14 per cent) patients were extubated in the immediatc postoperative period.

Perioperative blood or blood product requirements were not substantial. Using the closed-heart technique 92 ( 60 per cent) procedures required no blood products while the average requirements of the remaining 62 ( 40 per cent) were as follows: $2.0 \mathrm{u}$ packed red blood cells, $1.0 \mathrm{u}$ fresh frozen plasma, 0.8 u platelet concentrate. Not included in the analysis of blood product requirements is one patient who underwent three separate procedures for a persistent AAP and who required a large volume of blood products.

\section{Discussion}

Wolff-Parkinson-White Syndrome is part of a larger group of disorders collectively called the pre-excitation syndromes. These syndromes are best defined as those in which all or some part of ventricular muscle is prematurely activated in relation to atrial events. ${ }^{8}$ The unique anatomical abnormality in patients with this syndrome is a bridging of the atrioventricular sulcus by myocardial tissue capable of providing abnormal electrical continuity between the atria and ventricles. ${ }^{10,11}$ These accessory pathways are congenital and thought to be remnants of fetal atrioventricular muscular connections left in place by incomplete development of the annulus fibrosus. ${ }^{12}$

Characteristic ECG findings include a short P-R interval (less than $0.12 \mathrm{sec}$ ) and a prolonged QRS complex (greater than $0.10 \mathrm{sec}$ ) as a result of a delta wave. This consists of a slow rising, slurred QRS complex often with a bundle-branch block configuration. Recognizing that the QRS complex was quite variable in patients with this syndrome, Rosenbaum et al. suggested a classification of WPW into type A and type B in 1945. ${ }^{13}$ In type A premature activation of the left ventricle was said to occur with a resultant upright delta wave in precordial leads $V_{1}$ and $V_{2}$ with an ECG superficially resembling a right bundle branch block pattem. In type B premature activation of the right ventricle occurred with a resultant negative delta wave in those leads, and an ECG resernbling a left bundle branch block picture. This classification is now felt to be misleading; the picture is more accurately thought of as a continuum. The location of the pathway does not predict its electrophysiologic properties which are prognostically of paramount importance. ${ }^{12}$ The most common clinical presentation is recurrent supraventricular tachydysrhythmias secondary to atrioventricular re-entry.

Patients with PES undergoing AAP cryoblation surgery likely represent an extreme end of the spectrum of severity for this disorder. Nevertheless, they serve to illustrate the pathophysiologic potential of the pre-excitation syndromes. A prior benign clinical history with characteristic 
electrocardiographic changes in no way implies a benign future course. 3,4 .

Sudden death as the sole manifestation of WPW is not unrecognized $^{3,4} \mathrm{~A}$ history of atrial fibrillation, bidirectional tachycardia, the presence of more than one accessory atrioventricular pathway, and rapid conduction over the accessory pathway in atrial fibrillation were found to be important risk factors in patients with WPW progressing to ventricular fibrillation. ${ }^{3}$ There is no reliable way of preoperatively identifying this subgroup of patients without full EP studies. Consequently, the anaesthetist should anticipate, and be prepared to treat, this potentially fatal complication throughout the perioperative period in all WPW patients undergoing surgery.

Other cardiac disease was found in 18 (ten per cent) patients in our series. Although the presence of coronary artery disease, cardiomyopathy, idiopathic hypertrophic subaortic stenosis, and other conditions may well be coincidental, there is an association of WPW with certain congenital heart conditions. Besides ASD and Ebstein's anomaly (abnormally displaced tricuspid valve and atrialized right ventricle) there have been reports linking WPW with tricuspid atresia, corrected transposition of the great vessels, ventricular septal defect, and familial myocardial disease. ${ }^{15}$ Five to ten per cent of patients with Ebstein's anomaly have the WPW syndrome, ${ }^{16.17}$ and it is this association that has led to the suggestion that both conditions may result from some structural fault occurring during development of the tricuspid ring. ${ }^{5}$ Both associated congenital heart disease and coincidental cardiac conditions should be suught preoperatively as their occurrence is not infrequent and may profoundly influence the anaesthetic management.

Nervousness and anxiety may increase sympathctic nervous system activity producing an increased incidence of supraventricular tachy-dysrhythmias. In our series, one patient with SVT reported prior to induction had received no premedication while the other patient had been premedicated with a narcotic alone. The dosages of agents commonly used for premedication are unlikely to have a significant effect on the effective refractory periods of either the accessory pathway or the normal atrioventricular conduction system.

Although some texts advise cautious use of thiopentone to avoid aberrant conduction, ${ }^{18}$ this was not a problem in our experience. Where cardiovascular reserve is questionable thiopentone should be used sparingly, and consideration given to a narcotic-based induction. Fentanyl has been shown to have no effect on the accessory pathway, ${ }^{18}$ and is presumed to behave similarly to morphine in depressing atrioventricular conduction. Insertion of central lines using the Seldinger technique, wherein a flexible guidewire is inserted into the superior vena cava, may precipitate an episode of SVT if the wire inadvertently advanced into the atria. Continuous ECG monitoring and equipment for cardioversion should be readily available.

Various recommendations with regards to anaesthetic management have appeared in the literature. On the basis of one case, Van der Starre ${ }^{19}$ advocated neurolept analgesia using dnugs such as droperidol (0.3 $\mathrm{mg} \cdot \mathrm{kg}^{-1}$ ) and fentanyl $\left(0.07 \mathrm{mg} \cdot \mathrm{kg}^{-1}\right)$, or comparable anaesthetic techniques to produce cardiovascular stability. Similarly, Katz and $\mathrm{Kadis}^{18}$ believe that a balanced anaesthetic technique providing minimal circulatory disturbances is preferable. Other investigators including $\operatorname{lga}^{20}$ have emphasized suppression of sympathetic nervous system activity thus avoiding high circulating catccholamines pracipitating tachy-dysthythmias. Sadowski and Moyers ${ }^{21}$ and Kumazawa ${ }^{22}$ advocate moderate to deep levels of inhalational agents - with the aim of maintaining blood pressure and heart rate at or below preoperative values.

Gomez-Arnau et al. ${ }^{23}$ showed that droperidol (200$600 \mu \mathrm{g} \cdot \mathrm{kg}^{-1}$ ) is capable of depressing the antegrade conduction of the accessory pathway and thus reduces the risk of rapid ventricular dysrhythmias. They further proposed that by deptessing the retrograde conduction, droperidol may on occasion be able to block the re-entry mechanism. It was claimed that this did not interfere with intraoperative EP studies. Whether droperidol in smaller dosages (to avoid its undesirable central depressant and peripheral alpha-receptor blockade) would have a similar protective effect is unknown.

In our study, the incidence of supraventricular arrhythmias was unrelated to the choice of anacsthetic agent. Whether this result was influenced by underreporting - a recognized weakness of retrospective analyses - is unclear. Theoretical arguments for using the halogenated ethers preferentially over the alkanes can be made, however. Halothane has long been known to sensitize the myocardium to both endogenous and exogenous catecholamines to a greater extent than either of the ethers enflurane or isoflurane. ${ }^{24}$ Furthermore, Atlee et al. ${ }^{25,26}$ have shown that both halothane and enflurane induce adrenergic blockade and prolong conduction over the $\mathrm{A} \cdot \mathrm{V}$ node, but only halothane decreases conduction in the His-Purkinje system and ventricular myocardium, enhancing the opportunity for aberrant conduction and re-entry mechanisms. This is of particular relevance to the patient undergoing a short, non-cardiac procedurc for whom a pure narcotic relaxant technique is not an acceptable alternative.

The choice of muscle relaxant for the WPW patients is ulso controversial. Pancuronium is purportedly more likely to cause tachy-dysrhythmias than d-tubocurarine. ${ }^{27}$ Others have advocated avoiding gallamine and consider both pancuronium and d-tubocurarine to be preferable 
agents. ${ }^{19}$ In our experience arrhythmias bore no correlation with the use of either d-tubocurare or pancuronium. The newer muscle relaxants, essentially devoid of cardio. vascular side effects, would appear to be preferable, however.

The use of atropine as an antisialogue in patients with WPW has been discouraged. ${ }^{28}$ Atropine was used in three of our patients intraoperatively for brady-dysthythmias with no deleterious results. Consequently, we agree with Carmella et al. ${ }^{29}$ who do not feel there should be hesitancy in titrating repeated small doses of atropine to treat bradycardias in the WPW patient.

Intraoperative arrhythmias in our series were predominantly supraventricular tachy-dysrhythmias and were frequently associated with hypotension. The hypotension appears to be a consequence of general anaesthesia compromising compensatory mechanisms, as there was no overt correlation with preoperative symptomatology i.e., history of presyncope or syncope.

As illustrated by the three per cent incidence in our series, the potential for ventricular tachycardia or fibrillation necessitates continuous monitoring and prompt corrective action on the part of the anaesthetist. When profound cardiovascular disturbances mandate urgent treatment, synchronized cardioversion or defibrillation should be first-line therapy. ${ }^{30}$ Vagal manoeuvres are often of little help intraoperatively even when the haemodynamic disturbance is minimal, and can delay appropriate treatment. ${ }^{31}$ In our patients, initial treatment of an intraoperative SVT was cardioversion.

Antiarrhythmics are relatively contraindicated in arrhythmia surgery, due to potential suppression of the AAP, which can confound its identification and location by intranperative EP studies. Verapamil and propranolol were often administered during EP mapping, however, to slow AV node conductance and facilitate AAP identification. Due to a direct action on the slow calcium channels in the node proximal to the Bundle of His, verapamil terminates SVT by increasing A-V nodal refractoriness, and decreasing nodal conduction. ${ }^{32,33}$ Proptanolol depresses atrioventricular transmission by altering autonomic impulse traffic to the A-V node. Propranolol has also been proposed to have prophylactic value in reentrant SVT's, particularly those triggered or exacerbated by catecholamines, due to blockade of cardiac $\beta$-adrenoreceptors. ${ }^{34,35}$ Digoxin has no role acutely as it may accelerate anomalous conduction and precipitate malignant ventricular arrhythmias. ${ }^{36}$ Lidocaine has previously been advocated as the treatment of choice during general anaesthesia for SVT's with anomalous conduction because it depresses the accessory pathway. ${ }^{19,37}$ It was used successfully in two of our patients; however, its use in WPW cannot be recommended, since it increases AV conductance and has been reported to cause ventricular fibrillation when given during atrial fibrillation. ${ }^{38}$

Diflerentiation between supraventricular and ventricular rhythm disturbances may be difficult since AAP conduction can produce wide QRS-complexes, and should be considered when an arrhythmia fails to respond to a therapcutic modality as anticipated. Other therapeutic options available during cardiac surgery include both over- and under-drive electrical pacing which can control SVT during mapping, and firm manual compression of the exposed heart which is able to convert virtually all SVT to sinus rhythm. ${ }^{39}$

Other anaesthetic considerations unique to patients undergoing cryoablation for the WPW syndrome include the modest perioperative blood or blood product requirements, as well as the altered heparin pharmacokinetics during normothermic as opposed to hypothermic cardiopulmonary bypass. During normothermic cardiopulmonary bypass diligence and frequent supplemental heparin dosages are required to maintain adequate anti-coagulation.

Marked alterations in haemodynamic or electrical cardiac function may occur during mapping due to cardiac manipulations or injury to normal cardiac tissue. Vasopressor therapy subsequent to dislocation of the heart during mapping is often required. Furthermore, the development of hypotension during induced tachycardia may necessitate mapping being performed using cardiopulmonary bypass.

In contrast with other series, ${ }^{40}$ to date there have been no perioperative deaths in our group of patients using either the open or the closed technique. This, however, should not lead to a false sense of security on the part of the anaesthetist as the potential for significant morbidity and mortality certainly exists.

\section{Acknowledgement}

Our appreciation to Mrs. C. Toth for her secretarial help in the preparation of this manuscript.

\section{References}

1 Wolff $L$, Parkinson $J$, White $P D$. Bundle-branch block with short P-R interval in healthy young people prone to paroxysmal tachycardia. Am Hear J 1930; S: 685-704.

2 Gallagher JJ, Suensan RH, Sealy WG, Wallace AG. The Wolff-Parkinson-White syndrome and the pre-excitation dysrhythmias. Medical and surgical management. Med Clin N Am Jan 1976; 60: 101-22.

3 Klein GJ, Bashore TM, Sellers TD, Pritchet ELC, Smith WM, Gallagher JJ. Ventricular fibrillation in the Wolff-Parkinson-White syndrome. N Engl J Med 1979; 301: 1080-5. 
4 Kapian $M$, Cohen $K$. Ventricular fibrillation in the WolffParkinson-White syndrome. Am J Carciol 1969; 24: 259-64.

5 Gallagher $J$, Svenson RH, Sealy WC, Wallace $A G$, Gilbert $M$. Kasell J. The Wolff-Parkinson-White syndrome: the problem, evaluation, and surgical correction. Circulation 1975; 51: 767-83.

6 Guiraudon $C M$, Klein $G J$, Sharma $A D$, Jones $D L$, McLellan DG. Surgery for Wolff-Parkinson-White syndrome: further experience with a closed heart technique Circulation 1986; 74: 525-9.

7 Guiraudon GM, Klein GJ. Sharma $A D$, Jones $D L$, McLellan DG. Surgical ablation of posterior septal accessory pathways in the Wolff-Parkinson-White syndrome by a closed heart technique. J Thorac Cardiovasc Surg 1986; 92: 406-13.

8 Durrer D, Schuilenburg RM, Wellens HSJ. Pre-excitation revisited. Am J Cardiol 1970; 25: 690-97

9 Chung KS, Walsh TJ, Massve E. Wolff-Parkinson-White syndrome. Am Heart J 1965; 69: 116-33.

10 Becker $A E$, Anderson RH, Durrer $D$, et at. The anatomical substrates of Wolff-Parkinson-White syndrome: a clinicopathologic correlation in seven patients. Circulation 1978: 57: 870-9.

11 Seaiy WC, Gallagher JI, Pritchet ELC. The surgical anatomy of Kent bundles based on electrophysiological mapping and surgical exploration. J Thorac Cardiovasc Surg 1978; 76: 804-15.

12 Truex $R C$, Bishof $J K$, Hoffman EL. Accessory atrioventricular bundles of the developing human heart. Anat $\operatorname{Rec} 1958 ; 131 ; 45-59$.

13 Rosenbaum FF, Hecht HH, Wilson FN, Jahnston FD. The potential variations of the thorax and the esophagus in anomalous atrioventricular excitation (Wolff-ParkinsonWhite syndrome). Am Heart J 1945; 29: 281.

14 Klein GJ, Sharma AD. Milstein S. Initial evaluation of patients with the Wolff-Parkison-White syndrome. In: Cardiac Pre-excitation Syndromes. Benditt DC, Benson DW (Eds). Martinus Nijhoff Publishing, Boston, Mass, pp 305-19, 1986.

15 Newman BJ, Donoso E, Friedberg, $C K$. Arthythnias in the Wolff-Parkinson-White syndrome. Prog Cardiosasc Dis 1966; 9: 147-65.

16 Lev M, Gibson S, Miller DA. Ebstein's disease with Wolff-Parkinson-White syndrome. Am Heart $J$ 1955; 49: 724 .

17 Amat-y-Leon $F$, Wyndham $C, W u D$, et cl. Participation of fast and slow $A-V$ nodal pathways in tachycardias complicating the Wolff-Parkinson-White syndrome. Circulation 1977; 55: 663-8.

18 Katz J, Kadis $L$. Heart and Cardiovascular Syslem. $m$ : Anaesthesia and uncommon diseases. W.B. Saunders, Philadelphia 1973, pp 217-9.
19 Van der Starre PJA. Wolff-Parkinson-White syndrome during anesthesia. Ancsthcsiology 1978; 48: 369-71

$20 \mathrm{Iga} E$. Anesthetic managentent of WPW Syndrome. Jpn J Anesthesiol 1973; 23: 357-64.

21 Sadowski AR, Moyers JR. Anesthetic management of the Woltf-Parkinson-White syndrome. Anesthesiology 1979; 51: 553-6.

22 Kumazawa T. Wolff-Parkinson-White syndrome and anesthesia. Jpn I Anesthesiol 1970; 19: 68-73.

23 Gomez-Arnau J. Marque-Montes J, Avello F. Fentany] and droperidol effects on the refractoriness of the accessory pathway in the Wolff-Parkinson-White syndrome. Anesthesiology 1977; 146: 75-7.

24 Pratila MG, Pratilus V. Anesthetic agents and cardiac clectromechanical activity. Anesthesiology 1978; 49: 338-60.

25 Allee $J L$, Rusy $B F$. Atrioventricular conduction times and atrioventricular nodal conductivity during enflurane anesthesia in dogs. Anesthesiology 1977; 47: 498-505

26 Atlee $J L, R u s y B F, K r e u l J F, E b y T$. Supraventricular excitability in dogs during anesthesia with halothane and enflurane. Anesthesiology 1978; 49: 407-13

27 Anderson EJ, Rosenthal $M H$. Pancuronium bromide and tachyarthythmias. Crit Care Med 1975; 3: 13-5.

28 Homiyion-Kiff JG. The Wolff-Parkinson-White syndrome and general anaesthesia. $\mathrm{Br} \mathrm{J}$ Anaesth 1968; 40: 791-5.

29 Carmella LD, Malbez MS, Coudere E, Berger DL, Desmonis JM. L'anesthesie chez les sujets atteints de syndrome de pre-excitation ventriculaire. Can Anaesth Soc J 1983; 30: 185-90.

30 Meyer $A$, Greenberg $H$. Cardioversion of recurrent postoperative supraventricular tachycardia in WolffParkinson-White syndromc. Am J Cardiol 1966; 18: 904-6.

31 Sprague D, Mandel SD. Paroxysmal supraventricular tachycardia during anesthesia. Anesthesiology 1977; 46: $75-7$.

32 Spurell R, Krikler D, Souton E. Effects of verapanil on electrophysiological properties of anomalous atrioventricular conncetion in Wolff-Parkinson-White syndrome. Br Heart J 1974; 36: 256-64.

33 Braurwald $E$. Mechanism of action of calcium-channel blocking agents. N Engl J Med 1982; 307: 1618-27.

34 Jones RM, Broadbent MD, Adams AP. Anaesthetic considerations in patients with paroxysmat supraventricular tachycardia: a review and report of cases. Anaeschesia 1984; 39: 307-13.

35 Damato $A N$. Cardiac arrhythmias. In: Cecil's textbook of medicine. Beeson PB, McDermott W, Wyngaarden JB (Eds). 15th ed. Philadelphia: W.B.Saunders, pp 1242-68, 1979.

36 Hiss $R G$, Lamb LE. Electrocardiographic findings in 122,043 individuals. Circulation 1962; 25: 947-62 
37 Morris J. Supraventricular tachycardia of WolffParkinson-White syndrome converted to sinus thythm by intravenous lidocaine. J Med Assoe Alabama 1972; 42 . 271-2.

38 Dye $C L$. Atrial tachycardia in Wolff-Parkinson-White syndrome. Am J Cardiol 1969; 24: 265-8.

39 Klein GJ, Guiraudon, GM. Surgical therapy of cardiac arrhythmias, Cardiology Clinics $1983 ; 1 ; 323-40$.

40 Cox $J$, Gallagher JJ, Cam ME. Experience with 118 consecutive patients undergoing operation for the Wolff-Parkinson-White syndrome. J Therac Cardjovasc Surg 1985; 90: 490-501
Résumé

Les syndromes de pré-excitation ont une prévalence estimée d̀ 0.15 pour cent. Les progrès en cartographie ou mapping électrophysiologique et la sophistication accrue des techniques chirurgicales ont amené une augmentation croissante dans le traitement chirurgica! définitif de ces syndromes. Une étude rétrospective a évalué 181 patients subissant 197 procédures pour ablation chirurgicaie d' une voie accessoire atrioventriculaire entre juin 1981 et juin 1986. La moyenne d' âge des patients étaỉ de 30 ans (écart 6-66) avec une prépondérance de mâles (59 pour cent). Les maladies cardiaques associées ont été trowées chez 18 patients $(9.9$ pour cent). L'induction de I'anesthésie fut faite avec des barbituriques-relaxants ( 83 pour cent) ou narcotiques-benzodiazépine-reluxunt (17 pour cent) sans complication dans tous les cas. Pour 14 pour cent des cas une technique utilisant des narcotiques-relaxants a été employée pour le maintien de l'anesthésie alors que pour la balance on a urilisé de l'isoflurane (29 pour cent), de l'enflurane (34 pour cent), ou de ('halothane (22 pour cent). La relaxation musculaire a eté obtenue par la d-tubocurarine pour 35 procédures (18 pour cent) et du pancuronium pour le restant des procédures 162 ( 82 pour cent). Il n'y avait aucune corrélation significative entre les arythmies peropératoires at le type d'anesthésie utilisé. Tout en reconnaissant l'omiprésence d' une possibilité d'arythmie maligne, notre expérience (dans les limites de (" anclyse rétrospective) suggère que la majorité de ces patients peuvent subir avec succès une anesthésie générale stundard. 